\title{
Desempenho e características de carcaça do escargot francês (Helix aspersa maxima) alimentado com rações contendo diferentes óleos vegetais
}

\author{
Performance and carcass characteristics of "gros gris" (Helix aspersa maxima) fed with \\ different vegetable oils in diets
}

\author{
Carmino Hayashi $^{1^{*}}$ Claudemir Martins Soares ${ }^{2}$ Makoto Matsushita $^{3}$ \\ Eliana Maria Galdioli ${ }^{2}$ Igor Consoni Cocito $^{4}$
}

\section{RESUMO}

Objetivando avaliar a utilização de óleos vegetais de diferentes origens em rações no desempenho características de carcaça do escargot francês "gros gris" (Helix aspersa maxima), 240 animais com peso inicial médio de $0,11 \mathrm{~g}$, foram distribuídos em um delineamento inteiramente casualizado com seis tratamentos e quatro repetições com dez animais cada, em aquários de 12L. As rações foram formuladas de forma a diferirem quanto ao emprego (3\% da ração) dos óleos de soja, canola, girassol, linhaça, arroz e milho. Os valores médios de peso final, conversão alimentar, taxa de eficiência protéica, rendimento de carcaça, percentagem de concha e taxa de sobrevivência dos animais alimentados com as rações com os diferentes óleos não diferiram $(p>0,01)$ entre si. Os teores de umidade, cinza, proteína bruta e lipídeos totais e a relação ácidos graxos poliinsaturados/ácidos graxos saturados da porção comestivel dos animais submetidos as diferentes rações não foram influenciados $(p>0,05)$. Entretanto, os animais que receberam dieta com óleo de linhaça apresentaram o melhor $(p<0,05)$ relação $\omega 6 / \omega 3$ do que aqueles alimentados com rações com óleos de girassol e milho. Não foram observadas diferenças $(p>0,05)$ nos teores de umidade e cinza das conchas dos animais submetidos às diferentes rações. Por outro lado, os animais que receberam óleo de linhaça tiveram concha com menor $(p<0,05)$ teor de proteína que aqueles que receberam ração com óleo de soja. Concluiu-se que os óleos testados podem ser utilizados em rações para o escargot francês em fase de crescimento, porém, o óleo de linhaça promove melhor relação de $\omega 6 / \omega 3$ do que os óleos de girassol ou de milho na porção comestivel deste animal.

Palavras-chave: escargot, helicicultura, Helix aspersa, óleos vegetais

\begin{abstract}
Aiming to evaluate the use of different vegetable oil sources on performance and carcass characteristics of "gros gris" (Helix aspersa maxima) diets, two hundred forty snails with initial average weight of $0.11 \mathrm{~g}$ samples were distributed in an entirely randomized design with six treatments and four replications in twelve-liter aquaria. The diets were formulated to have differences on soybean, canola, sunflower, linseed, rice and corn oil inclusion at $3 \%$ of the diet. The average final weight, feed conversion, protein efficiency rate, carcass yields, percentage of shell and survival rates were not affected $(p>0.01)$ by the use of different oils. The moisture, ash, crud protein and fat contents and the polyunsaturated fatty acids/saturated fatty acids (PUAF/SAF) relation of the comestible part of the animal that were fed with different diets was not affected $(p>0.05)$. Therefore, the animals that received diets with linseed oil showed the best $\omega 6 / \omega 3$ relation than that one fed with diets with sunflower and corn oils. No differences were observed $(p>0.05)$ in the shell moisture and ash contents of the animals fed with the different diets. By other hand the animals fed with linseed oil had lower shell crud protein contents in relation to the ones fed diets with soybean oil. It was concluded that all the oils can be used on Helix aspersa maxima diets in growth phase; however, the linseed oil promotes better $\omega 6 / \omega 3$ relation than the sunflower and corn oils in the comestible part $f$ this animal.
\end{abstract}

Key words: escargot, heliciculture, Helix aspersa, snail, vegetable oils

\section{INTRODUÇÃO}

Os consumo de caracóis pelo homem ocorre desde a pré-história (RODRIGUES, 1991; FERRAZ,

'Biólogo, Professor, Doutor Titular, Departamento de Biologia, Universidade Estadual de Maringá.

${ }^{2}$ Biólogo, Doutor, Departamento de Biologia, Universidade Estadual de Maringá.

${ }^{3}$ Quimico, Professor Doutor Associado, Departamento de Química, Universidade Estadual de Maringá.

${ }^{4}$ Curso de Graduação em Agronomia, Departamento de Zootecnia, Universidade Estadual de Maringá.

*Av. Colombo 5790, Jardim Universitário, 97020-900, Maringá PR, Brasil. E-mail: chayashi@uem.br. 
1999). Atualmente o "escargot" é amplamente utilizado na alimentação humana em vários países da Europa, sendo a França seu principal consumidor (ROUSSELET, 1986).

A helicicultura tem se destacado como opção de cultivo alternativo no Brasil, especialmente na região Sul onde o clima é favorável a esta atividade, no tocante ao Helix aspersa maxima. Entretanto, são poucas as pesquisas visando aos aspectos do cultivo de "escargots" nas nossas condições climáticas. As espécies mais utilizadas em criações, e que apresentam características vantajosas como rusticidade, alta prolificidade, crescimento rápido, boa conversão alimentar e carne com excelente características organolépticas, são o caracol africano (Achatina fulica) e os "escargots" franceses "petit gris" (Helix aspersa) e "gros gris" (Helix aspersa maxima) (RODRIGUES, 1991; FERRAZ, 1999; HAYASHI et al., 2000b). Entretanto, o primeiro se adapta melhor em condições de clima quente (próximo a $30^{\circ} \mathrm{C}$ ), podendo ser cultivado em todo o território brasileiro. Os "escargots" de origem européia preferem baixas temperaturas, tendo 15 a $20^{\circ} \mathrm{C}$ como preferencial, desenvolvendo-se melhor na região sul do Brasil, principalmente no inverno. Por outro lado, os "escargots" do gênero Helix apresentam maior aceitação no mercado consumidor e valor econômico para a comercialização, devido às suas características desejáveis como a cor mais clara de sua carne.

O uso de rações para os caracóis proporciona bons índices de crescimento, melhor conversão alimentar (BARRIER, 1982; RIBAS, 1986; FERRAZ, 1999), facilidade de estocagem de alimento e de manejo, redução da ocorrência de doenças devido à melhor higiene no ambiente de criação. No entanto, não existem dados para a formulação de rações completas para estes animais (CUELLAR, 1986; ROUSSELET, 1986; SOARES et al., 1999; HAYASHI et al., 2000b) em função da escassez de dados sobre as exigências nutricionais dos diferentes nutrientes para as diferentes fases de desenvolvimento das espécies cultivadas. De modo geral, os criadores de escargot têm utilizado rações empíricas (HAYASHI et al., 2000b), normalmente à base farelos de trigo, soja e milho ou, concentrados de rações para aves misturados a milho e fontes de cálcio e fósforo, seja para os indivíduos recém nascidos, na fase de crescimento ou para os reprodutores (SOARES et al., 1999; RODRIGUES, 1991; FERRAZ, 1999).

As exigências nutricionais dos animais estão relacionadas com a sua fase de desenvolvimento, estado fisiológico, manejo e nível de produção desejada. A determinação das necessidades qualitativas e quantitativas dos nutrientes essenciais para as diversas fases de desenvolvimento das diferentes espécies é de fundamental importância para a adequada formulação de rações completas de modo a se obter bom desempenho, baixo custo e rentabilidade ideal nas criações. Desta forma, para o desenvolvimento, ainda melhor, da helicicultura e aumento na rentabilidade, deve-se buscar a determinação das exigências nutricionais assim como os níveis de utilização de alimentos convencionais e alternativos para as distintas fases de desenvolvimento das espécies mais utilizadas.

Entre as pesquisas já realizadas em relação a nutrição de caracóis comestíveis, destacam-se os trabalhos com fontes e níveis de cálcio de MELO et al. (1991), HAYASHI et al. (1998a) e LOBÃO et al. (1998) com o "gros gris", HAYASHI et al. (1998b) e PACHECO et al. (1998) com o A. fulica; com fontes e níveis de proteína para o A. fulica (HAYASHI et al., 1998; SOARES et al., 1999 e HAYASHI et al., 2000b); nível de proteína para o "gros gris" por MARKS \& JESS (1994) e SOARES et al. (2002), e os estudos sobre preferência alimentar ou à biologia e reprodução e manejo de $\boldsymbol{A}$. fulica (MONNEY, 1994; HAYASHI et al., 1997a; HAYASHI et al., 1998b, HAYASHI et al., 2000b) e da composição química de $\boldsymbol{A}$. fulica por ABOUA (1990).

Um dos principais nutrientes exigidos para qualquer espécie animal é a energia, sendo esta essencial para a manutenção, crescimento e reprodução (HEPHER, 1993). Para alguns animais, a fonte de gordura utilizada na ração pode influenciar significativamente o crescimento e a utilização dos alimentos. A energia dietética, de modo geral, provém do uso da proteína, lipídeos e carboidratos. Os lipídeos são a fonte de energia melhor utilizada pelos animais, além de fornecer energia metabólica, são requeridos para manutenção da estrutura e função da membrana celular e fornecem ácidos graxos essenciais ao animais.

Alguns ácidos graxos são essenciais para os animais e necessários em quantidades adequadas nas dietas para que estes se desenvolvam normalmente. Os diferentes óleos vegetais possuem distintos perfis de ácidos graxos. Alguns óleos, como o de linhaça, apresentam maiores teores dos ácidos graxos da serie ômega-3 e ômega-6. Conforme relatado por McKENZIE (2001), a composição em ácidos graxos do corpo dos animais reflete a composição dos mesmos no alimento consumido. $\mathrm{O}$ uso de diferentes óleos na dieta pode direcionar o perfil de ácidos graxos incorporado nos animais e conseqüentemente o valor nutricional do produto final. Desta forma, pode-se buscar dietas com níveis adequados de ácidos graxos 
para o desenvolvimento dos animais e ainda, produzir alimentos com perfis desejáveis destes para a alimentação humana.

Recentemente algumas pesquisas foram realizadas com animais, de diferentes grupos, como aves de postura, visando reduzir os teores de ácidos graxos saturados da gema do ovo por FARIAS FILHO (2000) e direcionar a composição de peixes (tilapia do Nilo) por HAYASHI et al. (2000a) e VISENTAINER et al. (2000) e mamíferos WEBSTER et al. (1999) variando a fonte de lipídeos empregada nas rações para obter produtos finais com teores elevados de ácidos graxos essenciais principalmente da serie ômega-3 e ômega6. Por outro lado, são inexistentes dados relacionados a esse aspecto ou ao uso de fontes de lipídeos para "escargots".

O objetivo do presente experimento foi avaliar o desempenho e características de carcaça do escargot francês " $\boldsymbol{H}$. aspersa maxima" em fase de crescimento alimentados com rações com óleos vegetais de diferentes origens.

\section{MATERIALEMÉTODOS}

O presente experimento foi realizado nas instalações do Laboratório de Zoologia Aplicada do Departamento de Biologia da Universidade Estadual de Maringá, de junho a setembro de 2000, com duração de 90 dias. Foram utilizados 240 escargot com peso médio de $0,11 \mathrm{~g}$, distribuídos em 24 aquários com capacidade para $12 \mathrm{~L}$ cada. Os aquários foram instalados em uma estante de aço sendo que estes eram cobertos por plástico escuro.

As rações experimentais com $20,0 \%$ de PB (Tabela 1) foram formuladas de forma a apresentarem mesma composição bromatológica, diferindo, entretanto quanto à origem do óleo vegetal, sendo utilizados os óleos de soja, canola, girassol, linhaça, arroz ou milho. Para a confecção das dietas, os ingredientes (milho e os farelos de soja, girassol e trigo) foram moídos em um moinho tipo faca com peneira com $0,50 \mathrm{~mm}$ de abertura, enquanto a farinha de ostra, o fosfato bicálcico e o calcário foram moídos em um moinho manual e peneirados em peneira com abertura de 0,25 mm. Após a mistura dos ingredientes, as dietas foram acondicionadas em geladeira $\left( \pm 5,00^{\circ} \mathrm{C}\right)$.

$\mathrm{O}$ fornecimento de água e ração foi realizado à vontade sendo que diariamente os comedouros eram monitorados para a adição de ração e manutenção da umidade, realizando-se retirada das fezes e pulverização de água. Caso houvesse ração com alta umidade, a mesma era retirada e seca em estufa de ventilação forçada a $105^{\circ} \mathrm{C}$ por 48 horas, para o cálculo da conversão alimentar.

O delineamento experimental utilizado foi o inteiramente casualizado com seis tratamentos e quatro repetições com 10 animais por repetição, considerandose como repetição o aquário com 10 animais.

Ao final do experimento, suspendeu-se o fornecimento das rações, sendo estes alimentados com fubá de milho por 48 horas. Após um período de 24 horas em jejum, os animais foram pesados e abatidos de acordo com a metodologia descrita por BARRIER (1982) e SOARES et al. (2002). Durante o abate, estes foram colocados em solução de 8:1:1 de água, vinagre e sal comum, respectivamente, por cinco minutos. Essa operação foi realizada duas vezes para a retirado do muco. Em seguida, os animais foram lavados em água corrente e colocados em água fervendo por cinco minutos, e novamente lavados, antes da retirada da concha e vísceras.

As características avaliadas foram peso final, conversão alimentar, taxa de eficiência protéica, percentagem de concha, rendimento de carcaça e sobrevivência. Para determinar o rendimento de carcaça e a percentagem de concha, utilizaram-se das expressões descritas por SOARES et al. (1999) como segue:

Percentagem de concha :

$\%$ Cch $=\frac{P c o}{P v} \times 100$

Onde: $\% C c h=$ percentagem de concha, $P c o$ $=$ peso médio das conchas e $P v=$ peso médio dos animais vivos.

Rendimento de carcaça:

$R C=\frac{P c a}{P v} \times 100$

Onde: $\mathrm{RC}=$ rendimento de carcaça, $\mathrm{Pca}=$ peso médio da carne e $\mathrm{Pv}=$ peso médio dos animais vivos.

As análises para as determinações da umidade, proteína bruta e cinzas da porção comestível e da concha dos animais foram realizadas segundo as metodologias de SILVA (1990). Por outro lado, o teor de lipídeos dos animais e das rações foram determinados segundo BLIGH \& DYER (1959). A transesterificação dos ácidos graxos foi realizada conforme método 5509 da ISO (1989) e os ésteres de ácidos graxos foram analisados através cromatógrafo gasoso 14-A (Shimadzu, Japão).

A taxa de eficiência protéica foi calculada segundo a expressão proposta por JAUNCEY \& ROSS (1982). 
Diariamente, pela manhã e tarde foram tomadas as temperaturas do ar com um termômetro de mercúrio a $10 \mathrm{~cm}$ de distancia da prateleira onde os aquários estavam instalados.

O modelo estatístico utilizado para as análises das variáveis estudadas foi:

$$
Y_{i j}=\mu+T i+e_{i j}
$$

onde: $Y_{\mathrm{ij}}=$ observação referente ao aquário j onde se utilizou o óleo i na ração, $\mu=$ constante geral, $T_{i}=$ efeito

do óleo i e $\mathrm{e}_{\mathrm{ij}}=$ desvio aleatório associado a cada observação $Y_{i j}$

Para as análises estatísticas os dados foram submetidos à análise de variância a $5 \%$ de probabilidade e em caso de diferenças estatísticas foi aplicado o teste de média de Tukey, através do programa computacional SAEG (Sistema de Análises
Estatísticas e Genéticas) descrito por EUCLYDES (1983).

\section{RESULTADOS E DISCUSSÃO}

Os valores médios da temperatura ambiente pela manhã e tarde observados durante o período em que se realizou o experimento foram de $15,05 \pm 5,21^{\circ} \mathrm{Ce}$ $20,26 \pm 3,75^{\circ} \mathrm{C}$, respectivamente, sendo que estes permaneceram dentro dos limites ideais recomendados por RODRIGUES (1991) e FERRAZ (1999) para o cultivo de "gros gris".

Os valores médios das características de desempenho e das características de carcaça do escargot francês $(\boldsymbol{H}$. aspersa maxima) submetidos a rações contendo diferentes óleos vegetais estão na tabela 2. Os valores obtidos para o peso final médio, conversão alimentar, taxa de eficiência protéica, rendimento de carcaça, percentagem de concha e taxa

Tabela 1 - Composição percentual e química das dietas experimentais (matéria natural) ${ }^{1}$

\begin{tabular}{|c|c|c|c|c|c|c|}
\hline \multirow{2}{*}{ Ingredientes (\%) } & \multicolumn{6}{|c|}{ óleos } \\
\hline & Soja & canola & girassol & linhaça & arroz & milho \\
\hline Milho & 25,00 & 25,00 & 25,00 & 25,00 & 25,00 & 25,00 \\
\hline Farelo de trigo & 19,91 & 19,91 & 19,91 & 19,91 & 19,91 & 19,91 \\
\hline Farelo de soja & 18,00 & 18,00 & 18,00 & 18,00 & 18,00 & 18,00 \\
\hline Farelo de girassol & 15,97 & 15,97 & 15,97 & 15,97 & 15,97 & 15,97 \\
\hline Fosfato bicálcico & 10,30 & 10,30 & 10,30 & 10,30 & 10,30 & 10,30 \\
\hline Farinha de ostra & 5,00 & 5,00 & 5,00 & 5,00 & 5,00 & 5,00 \\
\hline Calcário & 1,81 & 1,81 & 1,81 & 1,81 & 1,81 & 1,81 \\
\hline Óleo vegetal & 3,00 & 3,00 & 3,00 & 3,00 & 3,00 & 3,00 \\
\hline Sal comum & 0,50 & 0,50 & 0,50 & 0,50 & 0,50 & 0,50 \\
\hline Supl. Min. Vit. ${ }^{2}$ & 0,50 & 0,50 & 0,50 & 0,50 & 0,50 & 0,50 \\
\hline \multirow[t]{2}{*}{ BHT } & 0,02 & 0,02 & 0,02 & 0,02 & 0,02 & 0,02 \\
\hline & \multicolumn{6}{|c|}{ Composição bromatológica } \\
\hline $\mathrm{EM} /$ aves $(\mathrm{kcal} / \mathrm{kg})^{1}$ & 2450,00 & 2450,00 & 2450,00 & 2450,00 & 2450,00 & 2450,00 \\
\hline Fósforo total (\%) & 2,50 & 2,50 & 2,50 & 2,50 & 2,50 & 2,50 \\
\hline Cálcio (\%) & 5,00 & 5,00 & 5,00 & 5,00 & 5,00 & 5,00 \\
\hline Fibra bruta (\%) & 5,45 & 5,45 & 5,45 & 5,45 & 5,45 & 5,45 \\
\hline Lipídeos totais (\%) & 6,11 & 6,11 & 6,11 & 6,11 & 6,11 & 6,11 \\
\hline Metionina+cistina (\%) & 0,90 & 0,90 & 0,90 & 0,90 & 0,90 & 0,90 \\
\hline Lisina (\%) & 1,00 & 1,00 & 1,00 & 1,00 & 1,00 & 1,00 \\
\hline Proteína bruta (\%) & 20,00 & 20,00 & 20,00 & 20,00 & 20,00 & 20,00 \\
\hline AGPI/AGS ${ }^{3}$ & 2,72 & 2,59 & 2,04 & 2,87 & 2,50 & 1,81 \\
\hline$\omega 6 / \omega 3^{4}$ & 9,39 & 6,55 & 15,43 & 3,35 & 11,89 & 10,15 \\
\hline
\end{tabular}

${ }^{1}$ Com base nos valores tabelados por ROSTAGNO et al. (2000)

${ }^{2}$ Suplemento mineral e vitamínico para poedeiras comerciais, Composição por quilograma de produto: vitamina A - 2.250 .000 UI; vitamina D3 400.000,00 UI; vitamina E - 2.000,00 mg; vitamina K3 - 500,00 mg; vitamina B1 - $250 \mathrm{mg}$; vitamina B2 - $1.000 \mathrm{mg}$; vitamina b12 - 2.500 mcg; ác. Nicotínico - $3.750 \mathrm{mg}$; ac. Fólico - $75 \mathrm{mg}$; colina - $50.000 \mathrm{mg}$; biotina - $5 \mathrm{mg}$; ac. Pantotêico - $1.750 \mathrm{mg}$; ferro - $12.500 \mathrm{mcg}$; cobre - $1.500 \mathrm{mg}$; manganês - $12.500 \mathrm{mg}$; zinco - $15.000 \mathrm{mg}$, cobalto - $125 \mathrm{mg}$; iodo - $188 \mathrm{mg}$; selênio - $35 \mathrm{mg}$; antioxidante - $25.000 \mathrm{mg}$; veículo q.s.p - 1.000 mg. ${ }^{3}$ AGPI, AGS: ácidos graxos polinsaturados e ácidos graxos saturados, respectivamente.

${ }^{4} \omega 6, \omega 3^{3}$ ácidos graxos polinsaturados ômega- 6 e ômega- 3 , respectivamente. 
Tabela 2 - Valores médios das características de desempenho e de carcaça do escargot francês (Helix aspersa maxima) submetidos a dietas com diferentes óleos vegetais *

\begin{tabular}{|c|c|c|c|c|c|c|c|}
\hline \multirow{2}{*}{ Características } & \multicolumn{6}{|c|}{ Óleos } & \multirow{2}{*}{$\mathrm{CV}$} \\
\hline & soja & canola & girassol & linhaça & arroz & Milho & \\
\hline Peso total inicial $(\mathrm{g})$ & 0,11 & 0,11 & 0,11 & 0,11 & 0,11 & 0,11 & 0,00 \\
\hline Peso total final (g) & 6,50 & 7,69 & 7,49 & 7,05 & 6,65 & 6,61 & 28,15 \\
\hline Conversão alimentar & 1,85 & 1,74 & 1,73 & 1,68 & 1,75 & 1,66 & 23,44 \\
\hline Taxa de eficiência protéica & 2,85 & 3,20 & 2,87 & 2,99 & 2,64 & 2,98 & 30,21 \\
\hline Rendimento de carcaça (\%) & 31,54 & 29,43 & 28,47 & 32,65 & 33,33 & 33,02 & 12,87 \\
\hline Concha $(\%)$ & 11,54 & 12,11 & 10,28 & 11,10 & 11,22 & 11,22 & 14,42 \\
\hline Sobrevivência (\%) & 90,00 & 87,50 & 87,50 & 90,00 & 90,00 & 100,00 & 8,78 \\
\hline
\end{tabular}

* Valores de todas as características não diferiram entre si (p>0,01) pelo teste de Tukey

de sobrevivência dos animais alimentados com as diferentes rações não diferiram entre si $(p>0,01)$.

Os valores de conversão alimentar apresentados pelos animais indicam que estes apresentam boa conversão alimentar, reforçando os relatos de HAYASHI et al. (1997a) e FERRAZ (1999). Entretanto, os valores observados para $\boldsymbol{H}$. aspersa maxima neste estudo são piores que aqueles obtidos para A. fulica por SOARES et al. (1999) e HAYASHI et al. (2000b) e para o "gros gris" por SOARES et al. (2001). Em relação à taxa de eficiência protéica, os valores apresentado pelo "gros gris" foram inferiores aos obtidos para $\boldsymbol{A}$. fulica por HAYASHI et al. (2000b). Os diferentes índices de conversão alimentar e taxa de eficiência protéica observados entre A. fulica e "gros gris" devem relacionar-se com as diferenças no metabolismo destas espécies e condições ambientais onde se realizaram os experimentos.

Os valores de percentagem de concha observados por SOARES et al. (1999) e SOARES et al. (2001) utilizando dietas com diferentes níveis de proteína bruta para o "gros gris" e para o A. fulica, respectivamente, quando utilizaram rações com teor de proteína próximo às exigências destes animais, foram similares aos obtidos neste experimento, o que indica que os diferentes óleos vegetais não afetaram o estado nutricional dos animais, podendo desta forma serem utilizados na formulação de rações para o "gros gris".

Os valores da composição bromatológica da porção comestível e da concha do escargot francês submetidos a dietas com diferentes óleos vegetais estão na tabela 3. Não foram observadas diferenças ( $p>0,05)$ nos teores de umidade, cinza, proteína bruta e lipídeos totais e na relação ácidos graxos poliinsaturados/ácidos graxos saturados (AGPI/AGS) da porção comestível dos animais submetidos as diferentes rações. Entretanto, os animais que receberam dieta com óleo de linhaça apresentaram o melhor valor $(\mathrm{p}<0,05)$ da relação $\omega 6 / \omega 3$ do que aqueles que foram alimentados com rações com óleos de girassol e milho, apesar dos valores obtidos para estes não diferirem do uso dos óleos de soja, canola e arroz. Estes resultados demonstram que as diferentes composições em ácidos graxos exibidas nas rações devido as diferentes fontes lipídicas promovem diferenças nos tecidos destes animais.

Estes resultados estão de acordo com o relato de McKENZIE (2001) no qual as diferentes fontes de gordura podem levar a diferenças na composição em ácidos graxos depositados na carcaça. Pode-se, assim, direcionar o perfil em ácidos graxos do produto final de acordo da fonte de lipídeo empregada, devido às diferenças nas quantidades destes nas composições dos diferentes óleos, inclusive no que se refere ao teor de ácidos graxos das séries w3 no qual o óleo de linhaça é mais rico que os demais óleos aqui utilizados (FARIA FILHO, 2000; HAYASHI et al., 2000a; VISENTAINER, 2000). Desta forma, podese obter carne de escargot com diferentes relações dos ácidos graxos $\omega 6 / \omega 3$, para o consumo humano, modificando estes teores com o uso de diferentes óleos nas rações sem que o desempenho destes animais seja afetado.

Em relação à composição das conchas dos animais submetidos às diferentes rações, não foram observadas diferenças ( $p>0,05)$ nos teores de umidade e cinza. Por outro lado, os animais que receberam óleo de linhaça na ração mostraram-se com menor teor de proteína que aqueles que receberam ração com óleo de soja, não diferindo estes, entretanto, dos demais tratamentos.

Os resultados obtidos neste experimento indicam que os óleos testados, apesar de diferentes 
Tabela 3 - Composição bromatológica da porção comestível e concha do escargot francês (Helix aspersa maxima) submetidos a dietas com diferentes óleos vegetais (Matéria natural)*

\begin{tabular}{|c|c|c|c|c|c|c|}
\hline \multirow{2}{*}{ Características (\%) } & \multicolumn{6}{|c|}{ Óleos } \\
\hline & Soja & canola & girassol & linhaça & arroz & Milho \\
\hline & \multicolumn{6}{|c|}{ Porção comestível } \\
\hline Umidade & $74,26 \pm 2,18^{\mathrm{a}}$ & $73,85 \pm 1,41^{\mathrm{a}}$ & $75,29 \pm 2,02^{\mathrm{a}}$ & $73,85 \pm 1,41^{\mathrm{a}}$ & $75,29 \pm 2,02^{\mathrm{a}}$ & $75,33 \pm 2,49^{\mathrm{a}}$ \\
\hline Cinza & $0,96 \pm 0,20^{\mathrm{a}}$ & $1,14 \pm 0,14^{\mathrm{a}}$ & $1,13 \pm 0,28^{\mathrm{a}}$ & $1,06 \pm 0,38^{\mathrm{a}}$ & $1,20 \pm 0,23^{\mathrm{a}}$ & $1,14 \pm 0,21^{\mathrm{a}}$ \\
\hline Proteína bruta & $17,40 \pm 0,20^{\mathrm{a}}$ & $17,27 \pm 2,50^{\mathrm{a}}$ & $16,27 \pm 2,03^{\mathrm{a}}$ & $16,39 \pm 1,87^{\mathrm{a}}$ & $15,77 \pm 2,22^{\mathrm{a}}$ & $16,79 \pm 1,41^{\mathrm{a}}$ \\
\hline Lipídeos totais & $0,95 \pm 0,16^{\mathrm{a}}$ & $1,38 \pm 0,24^{\mathrm{a}}$ & $1,30 \pm 0,20^{\mathrm{a}}$ & $1,31 \pm 0,18^{\mathrm{a}}$ & $1,29 \pm 0,22^{\mathrm{a}}$ & $1,37 \pm 0,20^{\mathrm{a}}$ \\
\hline AGPI/AGS ${ }^{1}$ & $1,96 \pm 0,27^{\mathrm{a}}$ & $1,97 \pm 0,17^{\mathrm{a}}$ & $2,12 \pm 0,13^{\mathrm{a}}$ & $2,02 \pm 0,17^{\mathrm{a}}$ & $2,21 \pm 0,16^{\mathrm{a}}$ & $2,11 \pm 0,19^{\mathrm{a}}$ \\
\hline \multirow[t]{2}{*}{$\omega 6 / \omega 3^{2}$} & $6,42 \pm 0,90^{\mathrm{ab}}$ & $6,57 \pm 0,96^{\mathrm{ab}}$ & $7,02 \pm 0,63^{\mathrm{a}}$ & $5,12 \pm 0,24^{\mathrm{b}}$ & $6,56 \pm 0,53^{\mathrm{ab}}$ & $7,10 \pm 0,46^{\mathrm{a}}$ \\
\hline & \multicolumn{6}{|c|}{ Concha } \\
\hline Umidade & $21,68 \pm 2,46^{\mathrm{a}}$ & $21,40 \pm 0,23^{\mathrm{a}}$ & $19,85 \pm 1,03^{\mathrm{a}}$ & $19,57 \pm 0,53^{\mathrm{a}}$ & $17,43 \pm 0,66^{\mathrm{a}}$ & $21,11 \pm 2,66^{\mathrm{a}}$ \\
\hline Cinza & $49,24 \pm 4,79^{\mathrm{a}}$ & $42,25 \pm 1,17^{\mathrm{a}}$ & $41,83 \pm 1,14^{\mathrm{a}}$ & $42,41 \pm 0,61^{\mathrm{a}}$ & $43,84 \pm 0,66^{\mathrm{a}}$ & $42,76 \pm 4,12^{\mathrm{a}}$ \\
\hline Proteína bruta & $4,43 \pm 0,39^{\mathrm{a}}$ & $3,12 \pm 0,35^{\mathrm{ab}}$ & $3,17 \pm 0,17^{\mathrm{ab}}$ & $2,89 \pm 0,12^{\mathrm{b}}$ & $4,17 \pm 0,52^{\mathrm{ab}}$ & $4,26 \pm 0,21^{\mathrm{ab}}$ \\
\hline
\end{tabular}

${ }^{1}$ AGPI, AGS: ácidos graxos polinsaturados e ácidos graxos saturados, respectivamente.

$\omega 6, \omega 3$ : ácidos graxos polinsaturados ômega-6 e ômega-3, respectivamente.

*Valores em mesma linha seguidos de mesma letra não diferem entre si $(p>0,01)$ pelo teste de Tukey

origens, não apresentam características que afetem o desempenho, utilização do alimento e rendimento de carcaça do "gros gris" na fase de crescimento. Entretanto promovem diferenças na relação de $\omega 6 / \omega 3$. Assim sendo, os diferentes óleos devem ter suprido as exigências em ácidos graxos para estes animais.

\section{CONCLUSÃO}

Concluiu-se que os óleos de soja, canola, girassol, linhaça, arroz e de milho podem se utilizados em rações para o escargot francês em fase de crescimento, porém os óleos de soja, canola, linhaça e arroz promovem melhor relação de $\omega 6 / \omega 3$ na porção comestível deste animal.

\section{REFERÊNCIAS BIBLIOGRÁFICAS}

ABOUA, F. Chemical composition of Achatina fulica. Tropicultura, Brussels, v.8, n.3, p.121-122, 1990.

BARRIER, J. A criação do caracol. Lisboa : Litexa Portuga, 1982. 143p.

BELLAVER, C. et al. Radícula de malte na alimentação de suínos em crescimento e terminação. Pesquisa Agropecuária Brasileira, Brasilia, v.20, n.8, p.969-974, 1985.

BLIGH, E.G.; DYER, W.J. A rapid method of total lipid extraction and purification. Canadian Journal of Biochemistry and Physiology, v.37, n.8, p.911-917, 1959.

CUELLAR, R.C. et al. Helicicultura - Cria moderna de caracoles. Madrid : Mundi-Prensa, 1986. 142p.
EUCLYDES, R.F. Manual de utilização do programa SAEG (Sistema para Análises Estatísticas e Genéticas). Viçosa : UFV, 1983. 59p.

FARIAS FILHO, R.V. Efeito do óleo de linhaça e vitamina $E$ na dieta de poedeiras cobre o perfil de ácidos graxos da gema. 2000. 47f. Dissertação (Mestrado em Zootecnia) - Programa de Pós-graduação em Zootecnia, Universidade Estadual de Maringá.

FERRAZ, J. O escargot criação e comercialização. São Paulo : Ícone, 1999. 176p.

HANSSEN, J.E. Criação prática de escargots. São Paulo: Nobel, 1989. 113p.

HAYASHI, C. et al. Desempenho do escargot Achatina fulica, cultivados sob diferentes manejos. In: ENCONTRO BRASILEIRO DE MALACOLOGIA, 15., 1997, Florianópolis. Resumos... Florianópolis I; UFSC/SBM. 1997. p.97.

HAYASHI, C. et al. Avaliação de diferentes níveis de cálcio para o escargot gigante (Achatina fulica) em fase de crescimento. In: REUNIÃO ANUAL DA SOCIEDADE BRASILEIRA DE ZOOTECNIA, 35., 1998, Botucatu. Anais... Botucatu : SBZ, 1998a. V.4, p.162-163.

HAYASHI, C. et al. Efeito de diferentes níveis de cálcio em dietas para o escargot francês Helix aspersa maxima em fase de crescimento. In: REUNIÃO ANUAL DA SOCIEDADE BRASILEIRA DE ZOOTECNIA, 35., 1998, Botucatu. Anais... Botucatu : SBZ, 1998b. V.4, p.159-163.

HAYASHI, C. et al. Uso de diferentes óleos vegetais em dietas para a tilápia do Nilo (Oreochromis niloticus, L.), na fase inicial. In: REUNIÃO ANUAL DA SOCIEDADE BRASILEIRA DE ZOOTECNIA, 37., 2000, Porto Alegre. Anais... Porto Alegre: SBZ, 2000a. Disponível na Internet http//www.sbz.org.br/scripts/ anais2000/index.asp 
HAYASHI, C. et al. Diferentes fontes protéicas em dietas para o caracol gigante (Achatina fulica) na fase de crescimento. Revista Brasileira de Zootecnia, Viçosa, v.29, n.6, p.2082086, 2000b

HEPHER, B. Nutrición de peces comerciales en estanques. Balderas : Limusa, 1993. 406p.

ISO - INTERNATIONAL ORGANIZATION FOR STANDARDIZATION. Animal and vegetable fats and oils - preparation of methyl esters of fatty acids. Geneva: ISO. Method ISO 5509, 1989. p.01-06.

JAUNCEY, K.; ROSS, B. A guide to tilapia feeds and feeding. Scotland : University of Stirling, 1982. 111p.

LOBÃO, V.L. et al. Biologia e cultivo de escargots. Boletim do Instituto de Pesca, São Paulo, v.5, n.1, p.1-12, 1998 .

MARKS, R.J.; JESS, S. Effects of dietary protein source and contend on growth of Helix aspersa var. maxima snails. Snail Farming Research, v.5, n.1, p.64-74, 1994.

McKENZIE, D.J. Effects of dietary fatty acids on the respiratory and cardiovascular physiology of fish Comparative Biochemistry and Physiology, Oxford, v.128, p.607-621, 2001.

MELO, S.G. et al. Desenvolvimento ponderal do "escargot" Helix aspersa Müller (Gastropoda, Stylommatophora) com o emprego de diferentes fontes de cálcio. Boletim do Instituto de Pesca, São Paulo, v.18, n.único, p.31-40, 1991.

MONNEY, K.A. Effects of different dietary regimes on growth and reproductive function of farmed Achatina fulica Bowdich. Snail Farming Research, v.5, n.1, p.14-22, 1994

PACHECO, P. et al. Diferentes fontes de cálcio em dietas escargot gigante africano (Achatina fulica) e seu efeito no crescimento e rendimento de carcaça. Higiene alimentar, v.12, n.1, p.43-46, 1998

RIBAS, J. Criação de caracóis - nova opção econômica brasileira. São Paulo : Nobel, 1986. 123p.

RODRIGUES, M.P. Manual pratico para a criação de caracóis (escargots). 2.ed. São Paulo : Ícone Editora, 1991. $123 \mathrm{p}$.

ROSTAGNO, H.S. et al. Tabelas brasileiras para aves e suinos Composição de alimentos e exigências nutricionais. Viçosa : Imprensa Universitária, 2000. 141p.

ROUSSELET, M. Cria del caracol. Madrid : Mundi Prensa, 1986. 144p.

SILVA, D.J. Análise de alimentos (Métodos químicos e biológicos). Viçosa : Imprensa Universitária, 1990. 165p.

SOARES, C.M. et al. Exigência de proteína para o caracol gigante (Achatina fulica) em fase de crescimento. Acta Scientiarum, Maringá, v.21, n.3, p.683-686, 1999.

SOARES, C.M. et al. Exigência de proteína para o escargot francês (Helix aspersa maxima), em fase de crescimento. Revista Brasileira de Zootecnia, Viçosa, v.31, n.2 (supl.), p.835-841, 2002

VISENTAINER, J.V. et al. Quantificação de ácidos graxos ômega-3 (LNA, EPA e DHA), caracterização físico-química e composição de ácidos graxos em cabeças de tilápias jovens. In: CONGRESSO BRASILEIRO DE CIÊNCIA E TECNOLOGIA DE ALIMENTOS, 17., 2000, Fortaleza. Resumos... Fortaleza: UFC/SBCTA, 2000. p.5221.

WEBSTER, N.K. et al. Modulation of brain lipids of rats by various dietary oils: sunflower, high-oleic sunflower, olive, rapeseed and coriander oil. Nutrition Research, New York, v.19, n.7, p.997-1007, 1999. 